\title{
The effects of hearing deficits on student self-perceptions of social belonging, difficulty at school, and self-image
}

\author{
Lindsy Cox, Brittany Ruffo, Julianne Laird, Benjamin P. Schade, Karen H. Larwin \\ School Psychology, Youngstown State University, USA
}

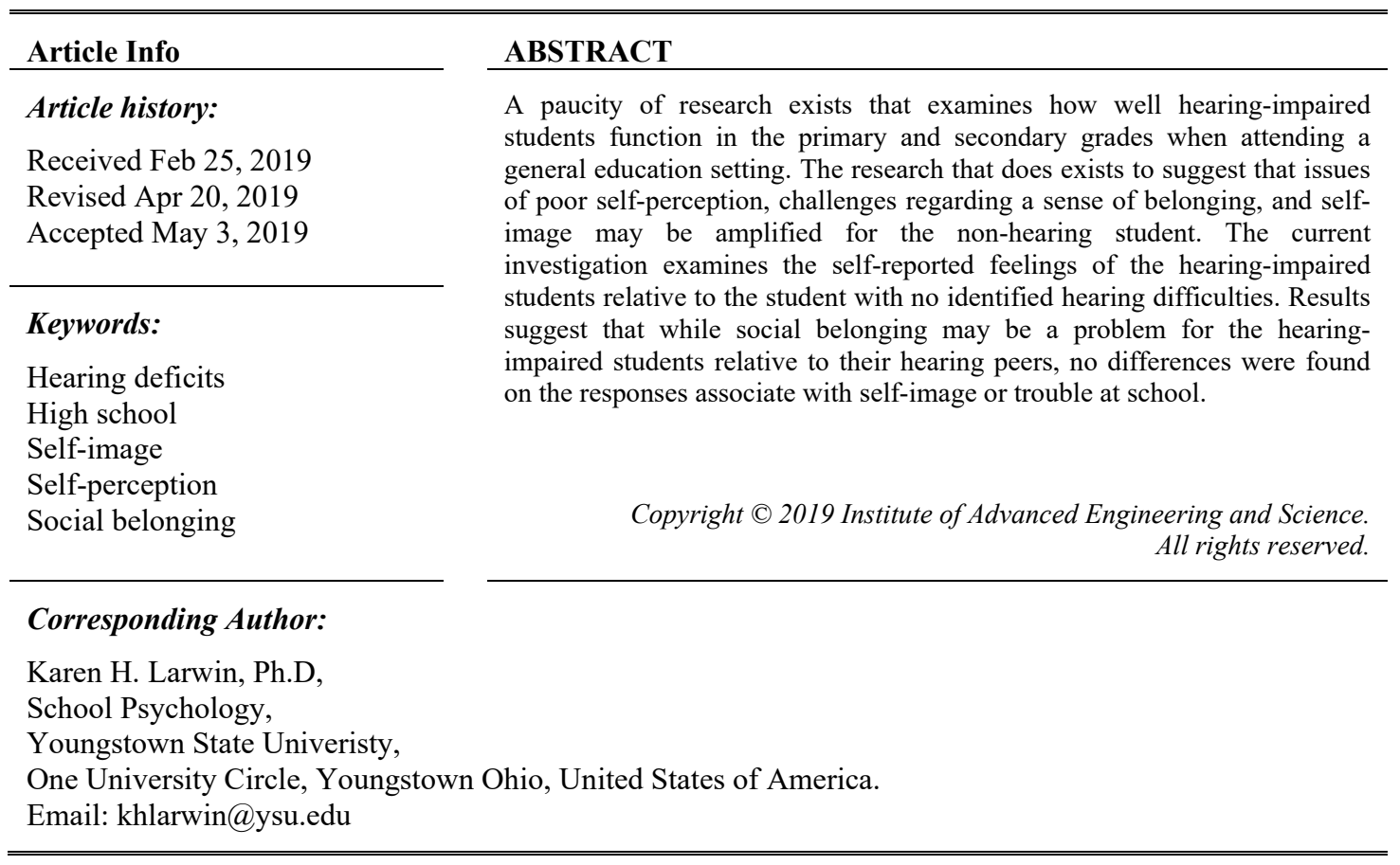

\section{INTRODUCTION}

Despite the hope that students of all disability backgrounds will experience equal access to educational experiences and opportunities as their typically developing peers, research has shown that, academically, non-hearing students typically under-perform in the classroom compared to their hearing peers of similar ages and grade levels [1]. These findings indicate that non-hearing students may not comprehend as much content as intended from instruction; this may be partially attributable to English language proficiency or inaccurate translation when interpreters are utilized [2]. However, Easterbrooks and BealAlvarez [3] found that many deaf and hard of hearing students demonstrate reading achievement levels above what is commonly believed possible for this population, some researchers have argued that the inability to lessen the disparity in overall academic achievement between non-hearing and hearing students indicates that educational institutions continue to lack effective methods of instruction to suit the learning styles of nonhearing students [4]. Thus, without specially designed instruction instruction tailored to non-hearing students' unique needs, these students may experience frustration and difficulty with completing assignments; these factors may precipitate overall perceived difficulty at school.

Educators who have knowledge of the foundations for differentiating instruction for non-hearing students may be more able to support their educational needs; because of this, non-hearing students may experience less trouble at school [5]. Garberoglio, Gobble, and Cawthon [6] noted while many teachers were confident in their instructional practices for students with hearing impairments, they lacked efficacy in their engagement of such students during their instruction. Eriks-Brophy and Whittingham [7] noted that while many teachers positively viewed their students with hearing impairments, many reported that their training programs did not adequately prepare them to teach students with these distinct instructional and social needs. 
A paucity of research has involved finding an explanation for the difficulty that non-hearing students have at school compared to their hearing peers in the same classroom setting [1]. In educational settings, non-hearing and hearing students have distinct needs related to their methods of communication, so educators need to be able to adapt their instructional support in response to these needs. There are three areas that may be particularly challenging for educators to foster success for their non-hearing students: academic integration (academic performance and classroom participation), academic differentiation, and social integration (interact with others, make friends, and be accepted by peers). Non-hearing students often face social isolation and struggle academically compared to their hearing peers [8]. It is important to note that trouble with school-based assignments and academic achievement can be exacerbated when non-hearing students are not adequately integrated into the social community with their hearing peers. Lund and Ross [9] found that students attending deaf-only schools reported perpetration and experienced victimization more frequently than students attending magnet schools serving students with disabilities, as the non-hearing students attending magnet schools were often excluded from the social culture of the school. However, Luckner and Ayantoye [10] found that itinerant teachers who support students with hearing impairments in the general education setting reported that "most general education teachers $(80 \%)$ understand the needs of the student, that the current placement is appropriate $(86 \%)$, and that the general education classroom with itinerant services is an effective model for this student $(88 \%)$, while $36 \%$ of such students were performing at or above grade level in reading, $28 \%$ are one year below, and $36 \%$ are performing two or more years below grade level".

Non-hearing students also report challenges related to social belonging. Despite findings that nonhearing students completed ratings of their feelings of acceptance and of feeling accepted at school similar to their typically hearing peers [11], communication methods appear to be the largest barrier when non-hearing students attempt to initiate peer entry in settings with multiple hearing peers [12]. In other words, a mismatch in communication methods and skills may reduce non-hearing students' perception of social belonging. Additionally, children with hearing impairments are more likely to be at risk for emotional and behavioral disorders, particularly in the areas of peer problems, conduct problems, and emotional symptoms [13, 14]. Parent ratings have indicated "significantly less prosocial behaviour in children" regarding children with hearing impairments [14].

However, others have found that increased participation in meaningful interactions with hearing peers positively affected the perception of social belonging for children with hearing loss [15]. Batten, Oakes, and Alexander [16] reaffirm that deficits in communication and hindered social interactions were the most common barriers to poor social relations with hearing peers. However, many hearing students reported personal beliefs that excluding their non-hearing peers was unacceptable during group social situations, though this became increasingly permissive during intimate situations [17].

Parents have commonly reported that they engage in behaviors that overprotect their non-hearing children to preempt social rejection [18]. Additionally, parents commonly reported that their non-hearing children refrained from participation in social activities, which often resulted in a smaller social circle [18]. However, Plotkin, Brice, and Reesman [19] discovered that parent stress and parent personality characteristics were strongly related to internalizing and externalizing behaviors in their deaf children. Thus, just as much as parents may want to protect their deaf children, they may inadvertently provoke undue emotional and behavioral concerns in their children. Finding a way to provide meaningful interactions and keep non-hearing students actively engaged and participating in the educational setting with their hearing peers could serve as protective factors for non-hearing students to increase their social belonging. The more distress a non-hearing student reports due to a perceived lack of social attachment to peers, the more likely that this perception will negatively impact their feelings of social belonging [19]. It is essential for educators to illicit social interactions between non-hearing and typically hearing peers so that non-hearing students may find acceptance among peer groups to exert a positive impact on social belonging [20].A related concern noted by Jambor and Elliott [21] for non-hearing students in school is the way they perceive themselves; specifically, non-hearing students' sense of self-image may be impacted by their perception or lack of a sense of belonging in their classroom. Jambor and Elliot [21] suggest that non-hearing students' levels of selfesteem may be positively related to their identification with the deaf community as their primary source of social inclusion. Non-hearing students who are integrated in inclusive classrooms may not experience this benefit due to being separated from the deaf community. Thus, educational placement alongside typically hearing peers may negatively impact non-hearing students' sense of self-image [20].

Educators may place lower expectations or decreased task requirements on non-hearing students; these educators may not be well adept with non-hearing students and their needs, which may additionally impact these students' opportunity to develop a positive self-image [20]. According to Rinat, Cinamon, and Most [22], lower environmental expectations from educators, and especially from parents, may negatively impact reported levels of future clarity and intensity among non-hearing students. Zheng [23] reports social

The effects of hearing deficits on student self-perceptions of social belonging, difficulty at ... (Lindsy Cox) 
comparisons, negative evaluations, and attitudes of others can damage the positive self-image of non-hearing students. When non-hearing students are placed in an inclusive classroom, they are exposed to more opportunities to compare themselves to their hearing peers and face those negative outcomes. However, students with hearing impairments "scored lower in some aspects of quality of life" (p. 47), notably in the area of relationships and sense of self while school placements did not appear to predict overall quality of life [24].

Based on a review of the current literature, it is suspected that non-hearing students will report significant differences in their perceptions of social belonging, trouble at school, and self-image compared to hearing peers compared to their typically hearing peers. The current study will evaluate these differences and elaborate on related trends by examining the self-reported feelings of the hearing-impaired students relative to the student with no identified hearing difficulties.

\section{RESEARCH METHOD}

The participants utilized in this study were retrieved from a publicly viewable pre-existing data set, the National Longitudinal Study of Adolescent Health [25]. Data analyzed in the present study involved responses from nine $(n=9)$ hearing impaired individuals and $449(n=449)$ hearing individuals.

Participants responded to questions regarding levels of their perceived social belonging, trouble at school, and positive self-image, measured using a Likert-type scale in which participated were required to respond to survey items based on five response options.

Response options for the "trouble at school" variable included: never, just a few times, about once a week, almost every day, and every day. Likewise, responses were coded using an ordinal scale with values respective to survey items utilizing the following format: $0=$ never, $1=$ just a few times, $2=$ about once a week, $3=$ almost every day, or $4=$ every day.

Response options for the "social belonging" and "positive self-image" variables included: strongly agree, agree, neither agree nor disagree, disagree, or strongly disagree. Likewise, responses were coded utilizing the following format: $1=$ strongly agree, $2=$ agree, $3=$ neither agree nor disagree, $4=$ disagree, or $5=$ strongly disagree.

Variables utilized to measure academic-related concerns included how often students reported trouble getting homework done and trouble paying attention in school. A reliability estimate was computed between these two variables using Cronbach $\alpha$, which indicated that the reliability of these two items was acceptable $(\alpha=.61)$. These two variables were subsequently merged and labeled the "trouble at school" variable in the present study.

Variables utilized to measure peer interactions included to what degree students reported feeling close to people at school and feeling that they were part of their school. A reliability estimate was computed between these two variables using Cronbach $\alpha$, which indicated that the reliability of these two items was acceptable $(\alpha=.72)$. These two variables were subsequently merged and labeled the "social belonging" variable in the present study.

Variables used to measure self-image included to what degree students reported liking themselves, having a lot to be proud of, and feeling they had good qualities. A reliability estimate was computed between these two variables using Cronbach $\alpha$, which indicated that the reliability of these two items was acceptable $(\alpha=.76)$. These three variables were subsequently merged and labeled the "positive self-image" variable in the present study.

Following a review of the literature, it is suspected that non-hearing students will report higher degrees of trouble at school, lower levels of social belonging, and lower levels of positive self-image when compared their typically hearing peers. To evaluate these hypotheses, the researchers performed one-way analysis of variance (ANOVA) that involved the preceding variables: social belonging, trouble at school, and positive self-image.

\section{RESULTS AND DISCUSSION}

The descriptive statistics for social belonging revealed a $M=2.16(S D=.82)$, with a skewness (.77) and kurtosis (.65) that were considered within a normal range. Based on the descriptive statistics, and normal skewness and kurtosis, the variable social belonging was found to be normally distributed. The Levene's Test of Homogeneity of variance indicated that the homogeneity of variance is tenable for social belonging across the different levels of individuals' current hearing status, $F(1.441)=.12, p=.73$.

The descriptive statistics for trouble at school revealed a $M=1.14(S D=.86)$, with a skewness $(.72)$ and kurtosis (.18) that were considered within a normal range. Based on the descriptive statistics, and normal skewness and kurtosis, the variable trouble at school was found to be normally distributed. The Levene's Test

Int. J. Eval. \& Res. Educ. Vol. 8, No. 2, June 2019: 280 - 285 
of Homogeneity of variance indicated that the homogeneity of variance is tenable for trouble at school across the different levels of individuals' current hearing status, $F(1.441)=.24, p=.63$.

The descriptive statistics for positive self-image revealed a $M=1.81$ ( $S D=.64)$, with a skewness (.59) and kurtosis (.11) that were considered within a normal range. Based on the descriptive statistics, and normal skewness and kurtosis, the variable positive self-image was found to be normally distributed. The Levene's Test of Homogeneity of variance indicated that the homogeneity of variance is tenable for positive self-image across the different levels of individuals' current hearing status, $F(1.453)=2.57, p=.11$.

A One-Way Analysis of Variance was conducted in order to assess if differences exist across social belonging, trouble at school, and positive self-image for individuals' current hearing status. The results of the One-Way Analysis of Variance is presented in Table 1. As displayed in Table 1, there was a significant difference found in the reported responses of social belonging between hearing and non-hearing participants.

Table 1. One-way ANOVA

\begin{tabular}{ccccc}
\hline \multicolumn{5}{c}{ Table 1. One-way ANOVA } \\
\hline Social Belonging & df & F & Sig. \\
\hline & Within Groups & 441 & & \\
& Total & 442 & & \\
Trouble at School & Between Groups & 1 & 0.451 & 0.502 \\
& Within Groups & 441 & & \\
& Total & 442 & & \\
Positive Self-Image & Between Groups & 1 & 0.414 & 0.52 \\
& Within Groups & 453 & & \\
& Total & 454 & & \\
\hline
\end{tabular}

It was hypothesized that non-hearing students would report higher degrees of trouble at school and lower levels of positive self-image compared to hearing students, contrary to findings by Milano and colleagues [11]. The results from the statistical analysis, however, indicated that no significant difference exists between non-hearing and hearing participants in this study regarding reports of trouble at school and positive self-image. The lack of significance found across these factors may be due to outside factors not addressed in this study regarding students' educational setting, social support networks, or availability of resources. The small number of non-hearing participants in this study may have also affected the results because of individual participants' unique life experiences, situational factors, and personal characteristics being exaggerated.

It was also posited that non-hearing students will report lower levels of positive self-image when compared to hearing students. A significant difference was indicated among reported agreement to the feeling of social belonging. Hearing individuals reported higher agreement to experiencing perceptions of social belonging in accordance to the collapsed factor compared to non-hearing individuals. This significant difference supports the hypothesis that hearing and non-hearing students will perceive different levels of social belonging. This significant difference may be due to characteristics of the classroom environment. Since non-hearing students may lag behind hearing peers academically, they may feel a lack of belonging with other students in the classroom [1]. The communication barriers noted by Martin and colleagues [12] between hearing and non-hearing students could also account for the lower reports of social belonging.

\section{CONCLUSION}

It was suspected that non-hearing students will report higher degrees of trouble at school, lower levels of social belonging, and lower levels of positive self-image when compared to their hearing students. To examine these hypotheses, the variables of social belonging, trouble at school, and positive self-image were statistically compared using one-way analysis of variance (ANOVA). Analyses revealed no significant difference between hearing and non-hearing students regarding trouble at school and positive self-image. However, significant differences were discovered for the social belonging factor such that typically hearing students reported higher levels of social belonging than their hard-of-hearing peers.

A limitation with the present study included the small sample of non-hearing students relative to the large sample of participants in the comparison group, which may have impacted the significance and magnitude of the results of the analyses. Additional confounding factors include variance in personal resilience factors, social support systems, concomitant disabilities, and academic placement available to non-hearing students.

Future recommendations to address the effects of hearing impairment on social belonging, trouble at school, and positive self-image should include an examination of educational setting and placement, as well as a balanced proportion of typically hearing peers. Future lines of inquiry could also examine the impact of

The effects of hearing deficits on student self-perceptions of social belonging, difficulty at ... (Lindsy Cox) 
protective factors, such as positive school environment, engagement in extracurricular activities, and degree of home-school collaboration. Additionally, any future replication studies and further lines of inquiry should include a larger sample size of non-hearing students, as well as a balanced comparison group.

\section{REFERENCES}

[1] Antia, S. D., Jones, P. B., Reed, S., \& Kreimeyer, K. H. (2009), "Academic status and progress of deaf and hard-ofhearing students in general education classrooms," Journal of Deaf Studies and Deaf Education, vol. 14, pp. 293-311.

[2] Qi, S., \& Mitchell, R. E. (2012), "Large-scale academic achievement testing of deaf and hard-of-hearing students: Past, present, and future," Journal of Deaf Studies and Deaf Education,vol. 17(1), pp. 1-18.

[3] Easterbrooks, S. R., \& Beal-Alvarez, J. S. (2012), "States' reading outcomes of students who are d/Deaf and hard of hearing," American Annals of the Deaf, vol. 157(1), pp. 27-40.

[4] Marschark, M., Leigh, G., Sapere, P., Burnham, D., Convertino, C., Stinson, M., \& Noble, W. (2006), "Benefits of sign language interpreting and text alternatives for deaf students' classroom learning," Journal of Deaf Studies and Deaf Education, vol. 11(4), pp. 421-437.

[5] Borgna, G., Convertino, C., Marschark, M., Morrison, C., \& Rizzolo, K. (2010), "Enhancing deaf students' learning from sign language and text: Metacognition, modality, and the effectiveness of content scaffolding," Journal of Deaf Studies and Deaf Education, vol. 16, pp. 79-100.

[6] Garberoglio, C. L., Gobble, M. E., \& Cawthon, S. W. (2012), "A national perspective on teachers' efficacy beliefs in deaf education," Journal of Deaf Studies and Deaf Education, vol. 17(3), pp. 367-383.

[7] Eriks-Brophy, A., \& Whittingham, J. (2013), "Teachers' perceptions of the inclusion of children with hearing loss in general education settings," American Annals of the Deaf, vol. 158(1), pp. 63-97.

[8] Stinson, M., \& Antia, S. (1999), "Considerations in educating deaf and hard-of-hearing students in inclusive settings," Journal of Deaf Studies and Deaf Education, vol. 4(3), pp. 163-175.

[9] Lund, E. M., \& Ross, S. W. (2016), "Peer victimization in students who are deaf and hard of hearing: Exploring educational placement," Journal of the American Deafness \& Rehabilitation Association (JADARA), vol. 50(2), pp. $20-44$.

[10] [10] Luckner, J. L., \& Ayantoye, C. (2013), "Itinerant teachers of students who are deaf or hard of hearing: Practices and preparation," Journal of Deaf Studies and Deaf Education, vol. 18(3), pp. 409-423.

[11] Milano, C., Upshire, T., Scarazzo, S., Schade, B. P., \& Larwin, K. H. (2016), "Adjustment and other factors related to high school aged students identified as hearing impaired," International Journal of Evaluation and Research in Education, vol. 5(4), pp. 255-260.

[12] Martin, D., Bat-Chava, Y., Lalwani, A., \& Waltzman, S. B. (2010), "Peer relationships of deaf children with cochlear implants: Predictors of peer entry and peer interaction success," Journal of Deaf Studies and Deaf Education, vol. 16(1), pp. 108-120.

[13] Laugen, N. J., Jacobsen, K. H., Rieffe, C., \& Wichstrom, L. (2016), "Predictors of psychosocial outcomes in hardof-hearing preschool children. Journal of Deaf Studies and Deaf Education, vol. 21(3), pp. 259-267.

[14] Stevenson, J., Kreppner, J., Pimperton, H., Worsfold, S., \& Kennedy, C. (2015), "Emotional and behavioural difficulties in children and adolescents with hearing impairment: A systematic review and meta-analysis," European Child \& Adolescent Psychiatry, vol. 24, pp. 477-496

[15] Bobzien, J., Richels, C., Raver, S. A., Hester, P., Browning, E., \& Morin, L. (2013), "An observational study of social communication skills in eight preschoolers with and without hearing loss during cooperative play," Early Childhood Education Journal, vol. 41(5), pp. 339-346.

[16] Batten, G., Oakes, P. M., \& Alexander, T. (2013), "Factors associated with social interactions between deaf children and their hearing peers: A systematic literature review" Journal of Deaf Studies and Deaf Education, vol. 19(3), pp. 285-302.

[17] Chilver-Stainer, J., Gasser, L., \& Perrig-Chiello, P. (2014), "Children's and adolescents' moral emotion attributions and judgements about exclusion of peers with hearing impairments," Journal of Moral Education, vol. 43(3), pp. 235-249.

[18] Lu, A., Tian, H., Yu, Y., Feng, Y., Hong, X., \& Yu, Z. (2015), "Peer attachment and social anxiety: Gender as a moderator across deaf and hearing adolescents," Social Behavior and Personality: An International Journal, vol. 43(2), pp. 231-239.

[19] Lu, A., Yu, Y., Hong, X., Feng, Y., Tian, H., \& Liao, J. (2014), "Peer attachment and loneliness among adolescents who are deaf: The moderating effect of personality," Social Behavior and Personality: An International Journal, vol 42(4), pp. 551-560.

[20] Plotkin, R. M., Brice, P. J., \& Reesman, J. H. (2013), "It is not just stress: Parent personality in raising a deaf child," Journal of Deaf Studies and Deaf Education, vol. 19(3), pp. 347-357.

[21] Jambor, E. \& Elliot, M. (2005), "Self-esteem and coping strategies among deaf students," Journal of Deaf Studies and Deaf Education, vol. 10(1), pp. 63-81.

[22] Rinat, M., Cinamon, R.G., \& Most, T. (2015), "What shapes adolescents' future perceptions? The effects of hearing loss, social affiliation, and career self- efficacy," Journal of Deaf Studies and Deaf Education, vol. 20, pp. 399-407.

[23] Zheng, J. (2013), "Measuring self-esteem of deaf/ hard of hearing college students. Journal of Special Education and Rehabilitation, vol. 14 (1-2), pp. 55-65.

Int. J. Eval. \& Res. Educ. Vol. 8, No. 2, June 2019: 280 - 285 
Int J Eval \& Res Educ.

[24] Schick, B., Skalicky, A., Edwards, T., Kushalnagar, P., Topolski, T., \& Patrick, D. (2012), "School placement and perceived qualify of life in youth who are deaf or hard of hearing," Journal of Deaf Studies and Deaf Education, vol. 18(1), pp. 47-61.

[25] Weight, G. S. (1999), "National longitudinal study of adolescent health." 